\title{
TGF- $\beta$ in jaw tumor fluids induces RANKL expression in stromal fibroblasts
}

\author{
CHIAKI YAMADA ${ }^{1,2}$, TOMONAO AIKAWA ${ }^{1}$, EMI OKUNO ${ }^{1}$, KAZUAKI MIYAGAWA ${ }^{1}$, KATSUHIKO AMANO ${ }^{1}$, \\ SOSUKE TAKAHATA $^{1}$, MASAAKI KIMATA ${ }^{1}$, MASAYA OKURA $^{1}$, SEIJI IIDA $^{2}$ and MIKIHIKO KOGO ${ }^{1}$ \\ ${ }^{1}$ First Department of Oral and Maxillofacial Surgery, Graduate School of Dentistry, Osaka University, Suita City, \\ Osaka 565-0871; ${ }^{2}$ Department of Oral and Maxillofacial Reconstructive Surgery, Okayama University \\ Graduate School of Medicine, Dentistry and Pharmaceutical Sciences, Kita-Ku, Okayama 700-8558, Japan
}

Received March 22, 2016; Accepted May 16, 2016

DOI: $10.3892 /$ ijo.2016.3548

\begin{abstract}
Odontogenic tumors and cysts, arising in the jawbones, grow by resorption and destruction of the jawbones. However, mechanisms underlying bone resorption by odontogenic tumors/cysts remain unclear. Odontogenic tumors/cysts comprise odontogenic epithelial cells and stromal fibroblasts, which originate from the developing tooth germ. It has been demonstrated that odontogenic epithelial cells of the developing tooth germ induce osteoclastogenesis to prevent the tooth germ from invading the developing bone to maintain its structure in developing bones. Thus, we hypothesized that odontogenic epithelial cells of odontogenic tumors/cysts induce osteoclast formation, which plays potential roles in tumor/ cyst outgrowth into the jawbone. The purpose of this study was to examine osteoclastogenesis by cytokines, focusing on transforming growth factor- $\beta$ (TGF- $\beta$ ), produced by odontogenic epithelial cells. We observed two pathways for receptor activator of $\mathrm{NF}-\kappa \mathrm{B}$ ligand (RANKL) induction by keratocystic odontogenic tumor fluid: the cyclooxygenase-2 (COX-2)/ prostaglandin E2 (PGE2) pathway through interleukin-1 $\alpha$ (IL-1 $\alpha$ ) signaling and non-COX-2/PGE2 pathway through TGF- $\beta$ receptor signaling. TGF- $\beta 1$ and IL- $1 \alpha$ produced by
\end{abstract}

Correspondence to: Dr Tomonao Aikawa, First Department of Oral and Maxillofacial Surgery, Graduate School of Dentistry, Osaka University, 1-8 Yamadaoka, Suita City, Osaka 565-0871, Japan

E-mail: aikawat@dent.osaka-u.ac.jp

Abbreviations: TGF- $\beta$, transforming growth factor- $\beta$; RANKL, receptor activator of $\mathrm{NF}-\mathrm{\kappa B}$ ligand; COX-2, cyclooxygenase-2; PGE2, prostaglandin E2; IL-1 $\alpha$ interleukin- $1 \alpha$; KCOT, keratocystic odontogenic tumors; OPG, osteoprotegerin; GAPDH, glyceraldehyde-3-phosphate dehydrogenase; RT-PCR, reverse transcription polymerase chain reaction

Key words: odontogenic tumor, keratocystic odontogenic tumor, transforming growth factor- $\beta$, interleukin- $1 \alpha$, receptor activator of $\mathrm{NF}-\kappa \mathrm{B}$ ligand odontogenic tumors/cysts induced osteoclastogenesis directly in the osteoclast precursor cells and indirectly via increased RANKL induction in the stroma.

\section{Introduction}

Recent research has indicated that the osteoclastogenesis induction factor, receptor activator of $N F-\kappa B$ ligand (RANKL), is involved in all bone resorption diseases regardless of inflammation or tumor induction (1). RANKL, which is expressed in cells such as osteoblasts, promotes osteoclast differentiation through signals from receptors expressed by osteoclast precursors $(1,2)$. In addition, RANKL induces osteoclast formation and bone resorption at the disease site in rheumatoid arthritis through expression by synovial fibroblasts $(3,4)$, tumor cells themselves (5) and lymphocytes (6). On the basis of the results of studies related to tooth germ development, cytokines and parathyroid hormone-related protein produced by the odontogenic epithelium promote osteoclast formation and protect the tooth germ from developing bone tissue by inducing RANKL expression in osteoblasts around the tooth germ and to be involved in the eruption of the tooth germ by regulating bone resorption $(7,8)$.

Transforming growth factor- $\beta$ (TGF- $\beta$ ) is a multifunctional cytokine that binds to its receptors on cell membranes, causes TGF- $\beta$ receptor phosphorylation, and activates $\operatorname{Smad} 2 / 3$ to induce intracellular signal transmission (9). Interleukin-1 $\alpha$ (IL-1 $\alpha$ ) is a multifunctional inflammatory cytokine (10). Both cytokines are expressed by the dental follicle (11). Furthermore, TGF- $\beta$, IL- $1 \alpha$, and tumor necrosis factor- $\alpha$ promote RANKL expression by the dental follicle, whereas the dental follicle is indicated to possess a latent ability to promote osteoclast formation (11-13). In addition, TGF- $\beta$ directly promotes osteoclast differentiation of osteoclast precursors (14), and IL-1 $\alpha$ also promotes osteoclast differentiation (15).

Typical neoplastic and cystic diseases of the jawbone include keratocystic odontogenic tumors (KCOTs), ameloblastomas, and follicular cysts; these diseases originate in the tooth germ epithelial cells and enhance resorption of the surrounding jawbone. These lesions, in the process of developing within the jawbone, inevitably absorb or destroy the surrounding jawbone. Although cyst epithelial cell proliferation $(16,17)$ and resorp- 
tion resulting from intracystic fluid-induced compression $(18,19)$ have been widely accepted, the molecular regulation of this biological event is still unclear. With respect to the mechanism underlying this intracystic fluid-induced pressure, the mechanism underlying bone resorption in the primary lesion has not been explained, and there has been no examination of the activation or involvement of osteoclasts in the area surrounding the cysts and tumors. A previous study by Oka et al (20) reported that IL- $1 \alpha$ produced by KCOTs promotes RANKL expression by stromal fibroblasts, suggesting the RANKL-mediating mechanism in the jawbones for tumors/ cysts expansion.

We therefore hypothesized that there is a potential cytokine network that induces both RANKL expression and bone resorption in jawbone osteoclasts, thereby serving as a mechanism for the growth of tumors and cysts.

Here we investigated the mechanism underlying RANKL expression in stromal fibroblasts to determine whether other cytokines produced by the odontogenic tumors and cell epithelium also affect this osteoclast formation and to suggest another mechanism underling tumors/cysts expansion in the jawbones.

\section{Materials and methods}

Cell culture and isolation of intracystic fluid. Subjects were patients who underwent surgical removal of jaw tumors/cysts at the First Department of Oral and Maxillofacial Surgery at Osaka University Dental Hospital. After the appropriate explanation of the use of specimens and samples for research and obtaining consent, we harvested appropriately removed odontogenic tumors and cysts (KCOTs, ameloblastomas, and follicular cysts). We simultaneously performed fine-needle aspiration of intracystic fluid. Stromal fibroblasts were isolated and cultured with an explant method. For the experiment, we used stromal fibroblasts that had undergone 2-9 subcultures.

Intracystic fluid was aspirated using a fine needle and centrifuged at $740 \times \mathrm{g}$ at $4^{\circ} \mathrm{C}$ for $10 \mathrm{~min}$; the supernatant was then collected and centrifuged twice more at $13,400 \mathrm{xg}$ at $4^{\circ} \mathrm{C}$ for $10 \mathrm{~min}$. This supernatant was then collected, sterilized using a filter with a pore size of $0.45 \mu \mathrm{m}$, and preserved at $-80^{\circ} \mathrm{C}$ until the experiment. For acid treatment of intracystic fluid, $12 \mathrm{M} \mathrm{HCl}$ was added (final concentration $0.5 \mathrm{M} \mathrm{HCl}$ ) to intracystic fluid, which was then incubated at $4^{\circ} \mathrm{C}$ for $30 \mathrm{~min}$. The acid was then neutralized with $10 \mathrm{M}$ $\mathrm{NaOH}$, at which point intracystic fluid was ready for use in the experiment.

Experiment reagents and antibodies. Recombinant human TGF- $\beta 1$ (R\&D Systems, Minneapolis, MN, USA), recombinant human IL-1 $\alpha$ (PeproTech, London, UK), and prostaglandin E2 (PGE2; Cayman Chemical Co., Ann Arbor, MI, USA) were used in the present experiment. The selective inhibitors used were an IL-1 receptor antagonist (IL-1Ra; PeproTech), TGF- $\beta$ receptor inhibitor (SB-505124; Sigma-Aldrich), and selective cyclooxygenase-2 (COX-2) inhibitor (CAY10404; Cayman Chemical Co.). The antibodies used were mouse monoclonal anti-TGF- $\beta 1,2,3$ antibody (clone 1D11; R\&D Systems), mouse monoclonal anti-human RANKL antibody (clone 70525.11; Sigma-Aldrich), goat anti-human COX-2 antibody (Cayman
Chemical Co.), and rabbit anti-phospho-Smad3 antibody (Rockland, Gilbertsville, PA, USA).

Total RNA extraction and reverse transcription polymerase chain reaction. Stromal fibroblasts were seeded into a 6-well culture plate (Corning) and proliferated to confluency, at which point the culture medium was changed. Stromal fibroblasts were incubated with or without a sample or in the presence or absence of a reagent, and total RNA was extracted using a RNeasy Mini kit (Qiagen, Hilden, Germany). In some experiments, intracystic fluid was reacted at room temperature for $1 \mathrm{~h}$ with mouse monoclonal anti-TGF- $\beta 1,2,3$ antibody or stromal fibroblasts were pretreated at $37^{\circ} \mathrm{C}$ for $1 \mathrm{~h}$ with $1 \mu \mathrm{M}$ TGF- $\beta$ receptor inhibitor, $50 \mathrm{ng} / \mathrm{ml} \mathrm{IL}-1 \mathrm{Ra}$, or $1 \mu \mathrm{M}$ COX-2 inhibitor; stromal fibroblasts were then incubated with or without a sample or in the presence or absence of a reagent, and total RNA was extracted. A total RNA template amount of 0.8-1.5 $\mu \mathrm{g}$ was used. After incubating total RNA with ReverTra Ace reverse transcriptase (Toyobo, Osaka, Japan), random hexamer primer (Applied Biosystems, Foster City, CA, USA), and RNase inhibitor (Promega, Madison, WI, USA) at $42^{\circ} \mathrm{C}$ for $30 \mathrm{~min}$, tRNA was then reacted at $99^{\circ} \mathrm{C}$ for $5 \mathrm{~min}$ and at $4^{\circ} \mathrm{C}$ for $5 \mathrm{~min}$ to synthesize cDNA. The primers used were RANKL (sense, 5'-GGGTATGAGAACTTGGGATT-3'; and antisense, 5'-CACTATTAATGCCACCGAC-3'), osteoprotegerin (OPG) (sense, 5'-CCTGACCACTACTACACAGACA-3'; and antisense, 5'-GTTAGCAGGAGACCAAAGACACT GCA-3'), and glyceraldehyde-3-phosphate dehydrogenase (GAPDH) (sense, 5'-CCATCACCATCTTCCAGGAG-3'; and antisense, 5'-GCATGGACTGTGGTCATGAG-3'). PCR using the RANKL primer consisted of 35 cycles of heat treatment at $94^{\circ} \mathrm{C}$ for $9 \mathrm{~min}$ followed by thermal denaturation at $94^{\circ} \mathrm{C}$ for $1 \mathrm{~min}$ and annealing at $57^{\circ} \mathrm{C}$ for $1 \mathrm{~min}$; elongation was then performed at $72^{\circ} \mathrm{C}$ for $10 \mathrm{~min}$. PCR using the OPG and GAPDH primers consisted of 30 cycles of annealing at $59^{\circ} \mathrm{C}$ for $1 \mathrm{~min}$.

Total cellular protein extraction and western blotting. Stromal fibroblasts were seeded into a $60-\mathrm{mm}$ cell culture dish (Corning) and proliferated to confluency. The culture medium was then changed to serum-free $\alpha$-MEM with $0.3 \%$ bovine serum albumin, and stromal fibroblasts were cultured for $16 \mathrm{~h}$. Culture was subsequently performed in serum-free $\alpha$-MEM with $0.3 \%$ BSA with or without a sample or reagent. Stromal fibroblasts were placed on ice for $20 \mathrm{~min}$ in RIPA lysis buffer $(50 \mathrm{mM}$ Tris- $\mathrm{HCl}, 150 \mathrm{mM} \mathrm{NaCl}, 1 \%$ Nonidet P-40, $0.5 \%$ sodium deoxycholate, $0.1 \%$ SDS, pH 7.4; Santa Cruz Biotechnology, Dallas, TX, USA) containing protease and phosphatase inhibitor cocktails (both from Sigma-Aldrich) and lysed. The cell lysate was then collected and centrifuged at $13,400 \times \mathrm{g}$ at $4^{\circ} \mathrm{C}$ for $20 \mathrm{~min}$; the supernatant was boiled in $5 \mathrm{X}$ SDS sample buffer and used in the following experiments. After performing electrophoresis on $20 \mu \mathrm{g}$ of total cellular protein in a $10 \%$ SDS polyacrylamide gel, the gel was transferred to a PVDF membrane (Bio-Rad, Hercules, CA, USA). As primary antibodies, rabbit anti-phospho-Smad3 (diluted 1:2,000) and goat anti-human COX-2 antibodies were diluted with T-PBS and reacted at $4^{\circ} \mathrm{C}$ for $16 \mathrm{~h}$. A luminescence reaction was performed with an Amersham ECL Plus kit (GE Healthcare, Uppsala, Sweden). Luminescent signals 


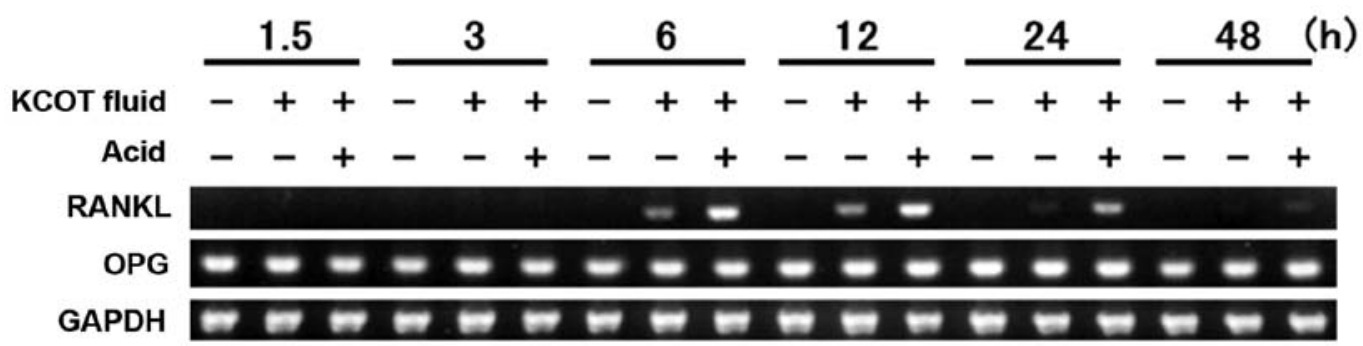

Figure 1. Effects of acid treatment of KCOT fluid on RANKL and OPG expression in KCOT stromal fibroblasts. KCOT stromal fibroblasts were cultured in the presence of $1 \%$ KCOT fluid for the times displayed above, and RT-PCR was used to examine RANKL and OPG expression. Intracystic fluid was found to induce RANKL expression, whereas OPG demonstrated no changes. Acid treatment of KCOT fluid enhanced RANKL expression.

were detected using a Kodak Gel Logic 2200 Imaging System (Carestream, Rochester, NY, USA).

Immunohistochemical staining. Tissues from KCOTs and ameloblastomas were fixed in $10 \%$ formalin buffer solution and embedded in paraffin. Four-micrometer-thick paraffin sections were created, and deparaffinized sections were used in immunohistochemical staining. Immunohistochemical staining was performed with a Vectastain ABC kit (Vector Laboratories, Burlingame, CA, USA) as per manufacturer's protocol. As primary antibodies, mouse monoclonal antiTGF- $\beta 1,2,3$ (diluted 1:10), mouse monoclonal anti-human RANKL (diluted 1:50), rabbit anti-phospho-Smad3 (diluted 1:500), and goat anti-human COX-2 antibodies (diluted 1:500) were diluted with blocking solution and reacted for $16 \mathrm{~h}$ at $4^{\circ} \mathrm{C}$.

Measurements of concentrations of TGF- $\beta 1$ and $I L-1 \alpha$. Concentrations of TGF- $\beta 1$ and IL- $1 \alpha$ in KCOT, ameloblastoma, and follicular cyst intracellular fluid were determined using a human TGF- $\beta 1$ ELISA kit and IL- $1 \alpha$ ELISA kit (both from R\&D Systems) while simultaneously measuring absorbance at $450 \mathrm{~nm}$ with a microplate reader (Model 680 , Bio-Rad) in accordance with the manufacturer's instructions. Experimental results are presented as means \pm standard deviation.

Measurement of concentration of prostaglandin E2. Stromal fibroblasts were proliferated in a 24-well culture plate (Corning) to confluency. After washing these stromal fibroblasts twice with serum-free $\alpha$-MEM culture medium containing $0.3 \%$ BSA, cells were cultured for $12 \mathrm{~h}$ in serum-free $\alpha$-MEM culture medium containing $0.3 \%$ BSA. The culture medium was then changed, and cells were further incubated for $6 \mathrm{~h}$ with or without a sample or reagent in serum-free $\alpha$-MEM culture medium containing $0.3 \%$ BSA. The culture supernatant was then collected and centrifuged at $13,400 \mathrm{x}$ g at $4^{\circ} \mathrm{C}$ for $10 \mathrm{~min}$. The resulting supernatant was then collected and preserved at $-80^{\circ} \mathrm{C}$ until used in experiments. Concentrations of PGE2 in the culture supernatant were determined using a PGE2 ELISA kit (Cayman Chemical Co.) while simultaneously measuring absorbance at $420 \mathrm{~nm}$ with the microplate reader, in accordance with the manual. Experimental results are expressed as means \pm standard deviation.

Statistical analyses. Statistical analyses were performed using Student's t-test. $\mathrm{P}<0.05$ was considered to be significant.

\section{Results}

Effects of KCOT fluid on RANKL and OPG expression in KCOT stromal fibroblasts. After KCOT stromal fibroblasts were cultured in the presence of KCOT fluid, reverse transcription polymerase chain reaction (RT-PCR) was used to examine RANKL and OPG expression. It was found that RANKL expression was induced by KCOT fluid at $6 \mathrm{~h}$ and the expression peaked at $12 \mathrm{~h}$. At $24 \mathrm{~h}$, RANKL expression attenuated. There were no changes in OPG expression at any point in time. Next, acid treatment was performed to determine the physiochemical properties of intracystic fluid; it was found that RANKL expression was enhanced at 6, 12, 24 and 48 h (Fig. 1).

Identical trends were observed in combinations of stromal fibroblasts and ameloblastoma fluid in three cases of ameloblastoma, stromal fibroblasts and follicular cyst fluid in two cases of follicular cysts, and stromal fibroblasts and KCOT fluid in three other cases of KCOT (data not shown). To ensure reproducibility in subsequent experiments, a large volume of intracystic fluid sample was collected, and the combination of KCOT stromal fibroblasts and KCOT fluid was chosen because of strong RANKL expression.

Effects of TGF- $\beta 1$ and IL-1 $\alpha$ on RANKL and OPG expression in KCOT stromal fibroblasts. The enhancement of physiological activity resulting from acid treatment indicated the possible involvement of key cytokines, such as TGF- $\beta$, in this process, and we subsequently addressed this point in detail. We also examined the effect of IL- $1 \alpha$, another important factor present in odontogenic cysts that is known to induce RANKL expression.

After KCOT stromal fibroblasts were cultured in the presence or absence of TGF- $\beta$ or IL-1 $\alpha$ for $12 \mathrm{~h}$, RT-PCR was used to examine RANKL and OPG expression. It was thus found that both TGF- $\beta$ and IL- $1 \alpha$ induced RANKL expression in a dose-dependent manner (Fig. 2A and B). In addition, when $\mathrm{KCOT}$ stromal fibroblasts were cultured in the combined presence of TGF- $\beta 1$ and IL- $1 \alpha$ for $12 \mathrm{~h}$, induction of RANKL expression was further enhanced. OPG expression was not affected by culturing with TGF- $\beta$ alone, IL- $1 \alpha$ alone, or a combination of the two (Fig. 2C).

Involvement of TGF- $\beta$ and $I L-1$ receptor signals in KCOT fluid-induced RANKL expression. To investigate whether TGF- $\beta$ is substantially present in KCOT fluid, we examined 

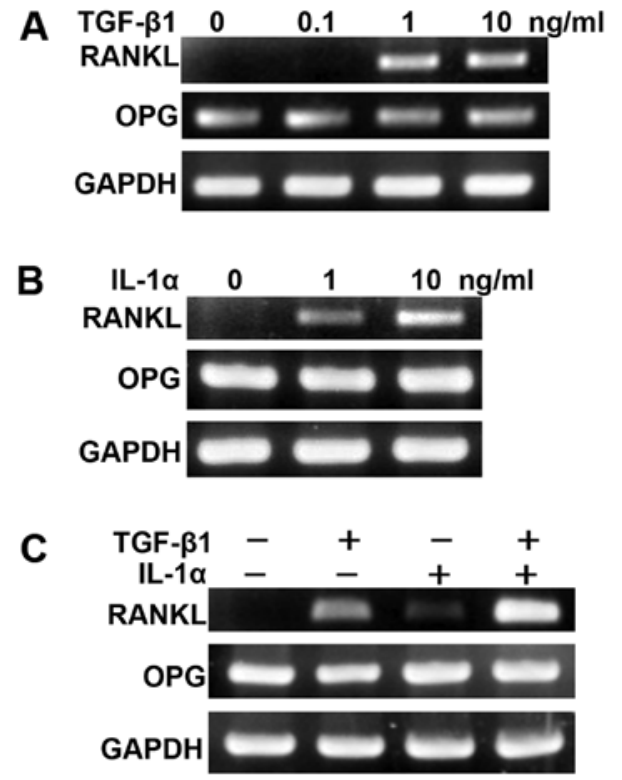

Figure 2. Effects of TGF- $\beta$ and IL-1 $\alpha$ on RANKL and OPG expression in KCOT stromal fibroblasts. (A and B) KCOT stromal fibroblasts were cultured in the presence of TGF- $\beta$ and IL- $1 \alpha$ for $12 \mathrm{~h}$, and RT-PCR was used to examine RANKL expression. Both TGF- $\beta 1$ (A) and IL-1 $\alpha$ (B) induced RANKL expression. OPG expression was unaffected. (C) Culturing in the presence of a combination of TGF- $\beta$ and IL-1 $\alpha$ for $12 \mathrm{~h}$ enhanced RANKL expression. OPG expression was unaffected.

Smad3 phosphorylation using western blotting. Consequently, Smad3 phosphorylation was observed 5 min after KCOT fluid stimulation; this phosphorylation was detected at $60 \mathrm{~min}$ as well (Fig. 3A). This result supports that TGF- $\beta$ in KCOT fluid activated TGF- $\beta$ receptor signals in KCOT stromal fibroblasts. To investigate whether TGF- $\beta$ in KCOT fluid mediates RANKL expression in KCOT fibroblasts, RT-PCR was used to examine RANKL and OPG expression in KCOT stromal fibroblasts pretreated with anti-TGF- $\beta$ antibody and cultured with KCOT fluid for $12 \mathrm{~h}$. It was found that KCOT fluidinduced RANKL expression was inhibited by anti-TGF- $\beta$ antibody in a concentration-dependent manner (Fig. 3B). In addition, when KCOT stromal fibroblasts were pretreated with TGF- $\beta$ receptor inhibitor and cultured for $12 \mathrm{~h}$ in the presence of KCOT fluid, RANKL expression was partially inhibited by TGF- $\beta$ receptor inhibitor (Fig. 3B). Incomplete blockade of anti-TGF- $\beta$ neutralizing antibody and TGF- $\beta$ receptor inhibitor on KCOT fluid-induced RANKL expression suggests that another factor in intracystic fluid regulates RANKL expression; we therefore investigated the involvement of IL- $1 \alpha$.

Following pretreatment with the TGF- $\beta$ receptor inhibitor, IL-1 receptor antagonist, or a combination of both, KCOT stromal fibroblasts were cultured in the presence of KCOT fluid for $12 \mathrm{~h}$. RT-PCR was then used to examine RANKL and OPG expression.

It was found that induction of RANKL expression when stromal fibroblasts were cultured in the presence of TGF- $\beta$ and IL-1 $\alpha$ was roughly equal to that when they were cultured with KCOT fluid. RANKL expression induced by KCOT fluid was partially inhibited by the IL-1 $\alpha$ receptor antagonist, strongly inhibited by TGF- $\beta$ receptor inhibitor, and completely inhibited by a combination of these two reagents (Fig. 4). These results suggest that TGF- $\beta$ and IL- $1 \alpha$ in KCOT fluid cooperate to induce RANKL expression in stromal fibroblasts.

Measurements of concentrations of TGF- $\beta 1$ and IL-1 $\alpha$ in odontogenic tumor and cyst fluid. Concentrations of TGF- $\beta 1$ and IL-1 $\alpha$ in the odontogenic tumor and cyst fluid were measured using ELISA. The mean concentration of TGF- $\beta 1$ in KCOT fluid in 10 cases was $7820.6 \pm 8625.2 \mathrm{pg} / \mathrm{ml}$, which was markedly high, whereas that of IL-1 $\alpha$ was also markedly high at $3410.8 \pm 1592.8 \mathrm{pg} / \mathrm{ml}$. The mean concentrations of TGF- $\beta 1$ and IL-1 $\alpha$ in intracystic fluid in three cases of ameloblastoma were $606.8 \pm 264.5$ and $387.3 \pm 654.0 \mathrm{pg} / \mathrm{ml}$, respectively. Mean concentrations of TGF- $\beta 1$ and IL- $1 \alpha$ in intracystic fluid in the five cases of follicular cyst were $5142.2 \pm 5338.1$ and
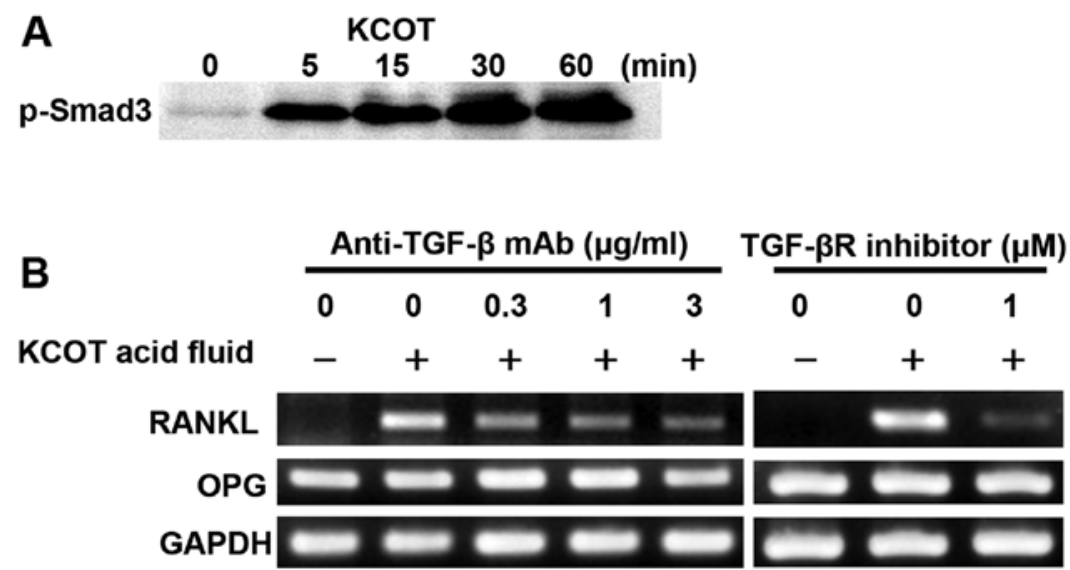

Figure 3. Effects of phosphorylation of Smad3 in KCOT stromal fibroblasts, and effects of anti-TGF- $\beta$ antibody and TGF- $\beta$ receptor inhibitor on KCOT fluid-induced RANKL expression in KCOT stromal fibroblasts. (A) KCOT stromal fibroblasts were stimulated with $1 \%$ KCOT fluid, and phosphorylation of Smad3 was examined by western blotting. KCOT fluid stimulation was found to induce phosphorylation of Smad3. (B) KCOT stromal fibroblasts were cultured for $12 \mathrm{~h}$ in the presence of $1 \%$ KCOT fluid (with or without acid treatment as indicated by KCOT acid fluid) pretreated for $1 \mathrm{~h}$ with the above-displayed concentrations of anti-TGF- $\beta$ antibody, and RT-PCR was used to examine RANK and OPG expression. KCOT stromal fibroblasts were also cultured for $12 \mathrm{~h}$ in the presence of KCOT fluid following $1 \mathrm{~h}$ of pretreatment with $1 \mu \mathrm{M}$ of TGF- $\beta$ receptor inhibitor, and RT-PCR was used to examine RANKL and OPG expression. Intracystic fluid-induced RANKL expression was inhibited by anti-TGF- $\beta$ antibody in a concentration-dependent manner and by TGF- $\beta$ receptor inhibitor. 


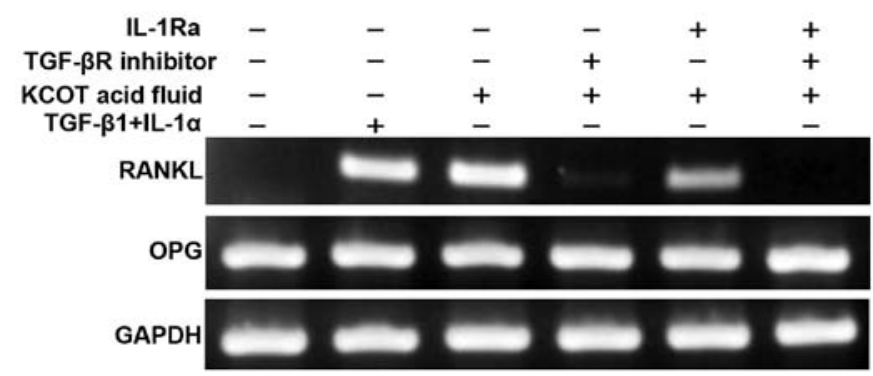

Figure 4. Effects of TGF- $\beta$ receptor inhibitor and IL-1 receptor antagonist on KCOT fluid-induced RANKL expression. The TGF- $\beta$ receptor inhibitor $(1 \mu \mathrm{M})$ and IL-1 receptor antagonist $(50 \mathrm{ng} / \mathrm{ml})$ were used to pretreat KCOT stromal fibroblasts for $1 \mathrm{~h}$. These KCOT stromal fibroblasts were then cultured for $12 \mathrm{~h}$ in the combined presence of IL- $1 \alpha(1 \mathrm{ng} / \mathrm{ml})$ and TGF- $\beta 1$ $(1 \mathrm{ng} / \mathrm{ml}$ ) or $1 \%$ KCOT fluid (with or without acid treatment as indicated by KCOT acid fluid), and RT-PCR was used to examine RANKL expression. The increase in RANKL expression induced by the combination of TGF- $\beta 1$ and IL-1 $\alpha$ was approximately equal to the increase induced by intracystic fluid. Intracystic fluid-induced RANKL expression was partially inhibited by the IL-1 receptor antagonist, strongly inhibited by TGF- $\beta$ receptor inhibitor, and completely inhibited by a combination of the two.

$73.5 \pm 102.7 \mathrm{pg} / \mathrm{ml}$, respectively; both of these concentrations were relatively low compared with those of KCOT (Fig. 5).

Investigation of localization of TGF- $\beta$, phosphorylated Smad3, RANKL, and COX-2 in KCOT and ameloblastoma tissues. Immunohistochemical staining was performed to examine whether induction of RANKL expression in stromal fibroblasts actually occurs within lesions via our model. Staining for TGF- $\beta$ in the KCOT tissue was strongly positive in the cyst epithelium, positive in lymphocytes that had infiltrated the interstitial tissue, positive in endothelial cells, and weakly positive in stromal fibroblasts. Staining for TGF- $\beta$ in ameloblastoma was positive in tall columnar epithelial cells, weakly positive in asteroid cells, positive in endothelial cells, and weakly positive in stromal fibroblasts. Staining for phosphorylated Smad3 in KCOT was strongly positive in all layers of the cyst epithelium, particularly in basal cell nuclei, and was positive in stromal fibroblast nuclei. Staining for phosphorylated Smad3 in ameloblastoma was positive in tall columnar epithelial cells, endothelial cells, and stromal fibroblasts (Fig. 6). Staining for RANKL in the KCOT tissue was strongly positive in infiltrative lymphocytes, positive in the cyst epithelium, and positive in stromal fibroblasts. Staining for RANKL in ameloblastoma was weakly positive in epithelial cells and stromal fibroblasts. Staining for COX-2 in the KCOT tissue was strongly positive in the cornified layer of the cyst epithelium and positive in stromal fibroblasts, infiltrative lymphocytes, and endothelial cells. Staining for COX-2 in ameloblastoma was positive in epithelial cells, stromal fibroblasts, and endothelial cells (Fig. 7).

Mechanisms of COX-2 expression, PGE2 synthesis, and RANKL expression in KCOT stromal fibroblasts. Both TGF- $\beta$ and IL- $1 \alpha$ in intracystic fluid were shown to induce RANKL expression in stromal fibroblasts, whereas a combination of TGF- $\beta$ and IL- $1 \alpha$ was shown to strongly induce RANKL expression. The mechanism by which IL-1 $\alpha$ induces RANKL expression is mediated by COX-2 and PGE2 synthesis $(20,21)$. Therefore, we investigated whether TGF- $\beta$ is also involved in these processes and whether this PGE synthesis promotes the induction of RANKL expression in stromal fibroblasts.

We examined the concentration of COX-2 protein resulting from culturing stromal fibroblasts for 6 and $12 \mathrm{~h}$ in the presence of KCOT fluid, TGF- $\beta 1$, IL- $1 \alpha$, and a combination of TGF- $\beta 1$ and IL- $1 \alpha$. It was found that although TGF- $\beta 1 \mathrm{did}$ not increase COX-2 protein expression at 6 or $12 \mathrm{~h}$, IL- $1 \alpha$ did increase its expression. In addition, the combination of TGF- $\beta 1$ and IL- $1 \alpha$ synergistically increased COX- 2 protein expression. Furthermore, KCOT fluid yielded an increase in COX-2 protein expression roughly equivalent to that yielded by a combination of TGF- $\beta 1$ and IL- $1 \alpha$ (Fig. $8 \mathrm{~A}$ ).

Next, we cultured KCOT stromal fibroblasts for $12 \mathrm{~h}$ in the presence of KCOT fluid following pretreatment with the TGF- $\beta$ receptor inhibitor, IL-1 receptor antagonist, or a combination of both and then examined subsequent COX-2 expression. It was found that KCOT fluid-induced COX-2 protein expression
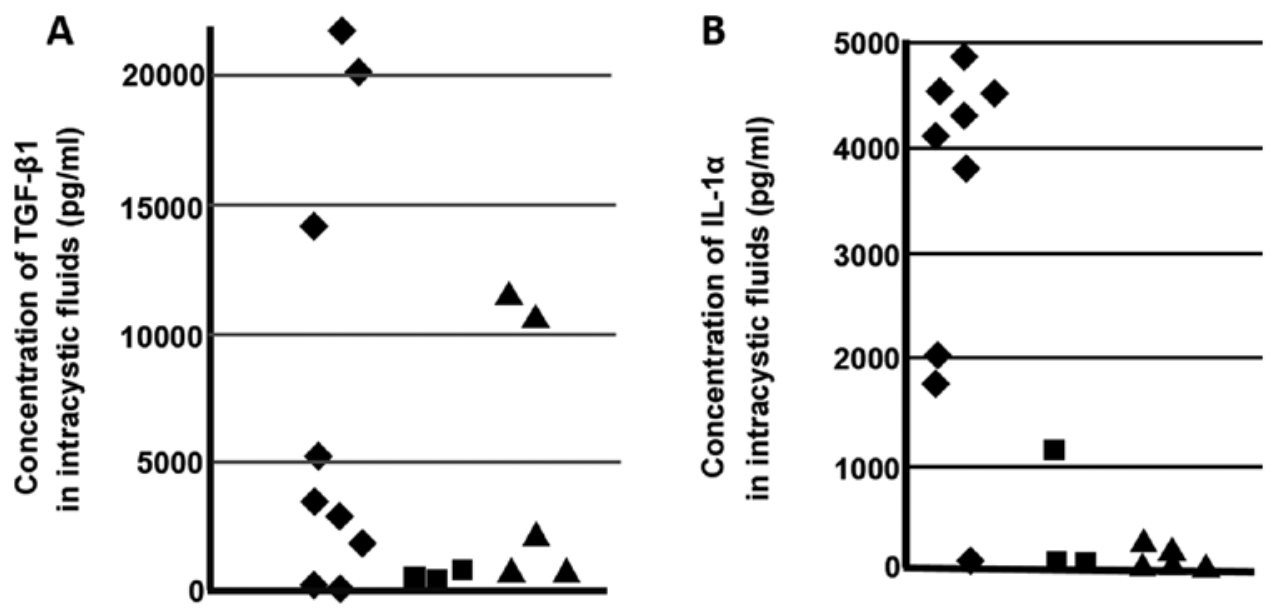

Figure 5. Concentrations of TGF- $\beta 1$ and IL- $1 \alpha$ in odontogenic tumor and intracystic fluid. Concentrations of TGF- $\beta 1$ (A) and IL-1 $\alpha$ (B) in KCOT ( $\bullet$ ), ameloblastoma ( $\mathbf{(})$, and follicular cyst ( $\mathbf{\Delta})$ fluid were measured with ELISA. In KCOT, the mean concentrations of TGF- $\beta 1$ and IL- $1 \alpha$ were $7820.6 \pm 8625.2$ and $3410.8 \pm 1592.8 \mathrm{pg} / \mathrm{ml}$, respectively $(\mathrm{n}=10)$. In ameloblastoma, the mean concentrations of TGF- $\beta 1$ and IL-1 $\alpha$ were $606.8 \pm 264.5 \mathrm{and} 387.3 \pm 654.0 \mathrm{pg} / \mathrm{ml}$, respectively $(\mathrm{n}=3)$. In follicular cyst, the mean concentrations of TGF- $\beta 1$ and IL-1 $\alpha$ were $5142.2 \pm 5338.1$ and $73.5 \pm 102.7 \mathrm{pg} / \mathrm{ml}$, respectively $(\mathrm{n}=5)$. 
A

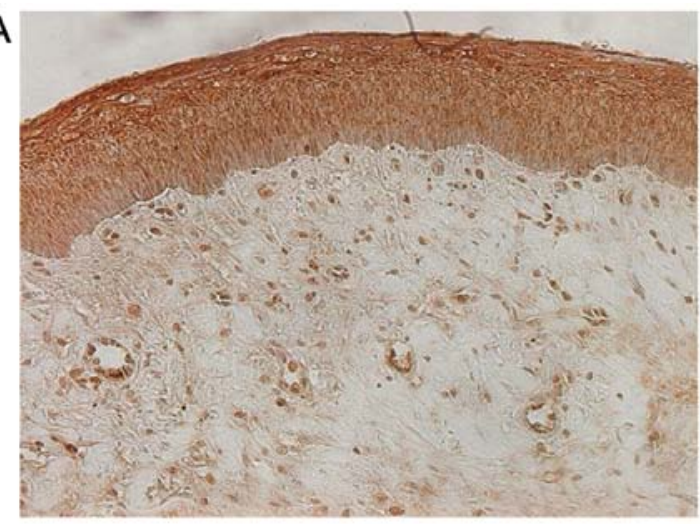

C

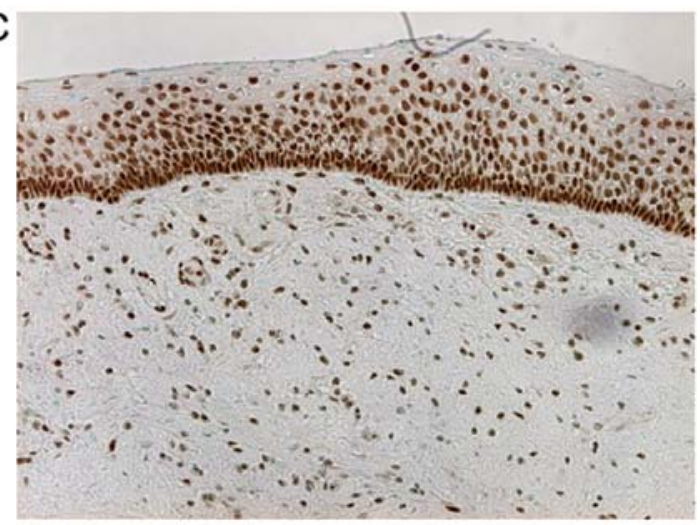

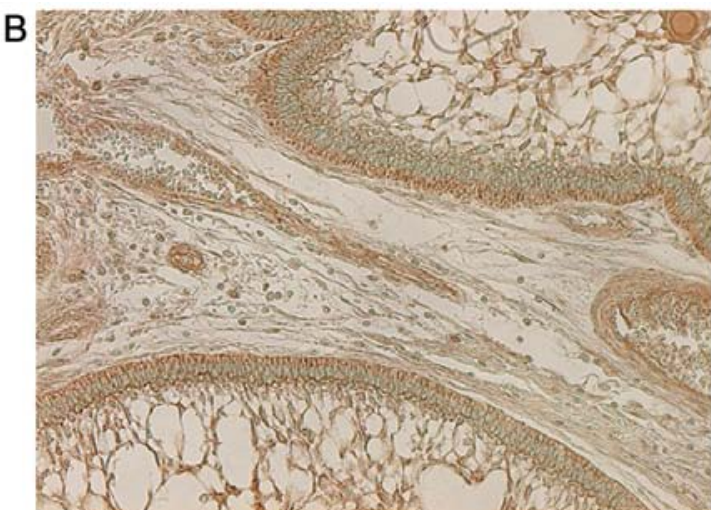

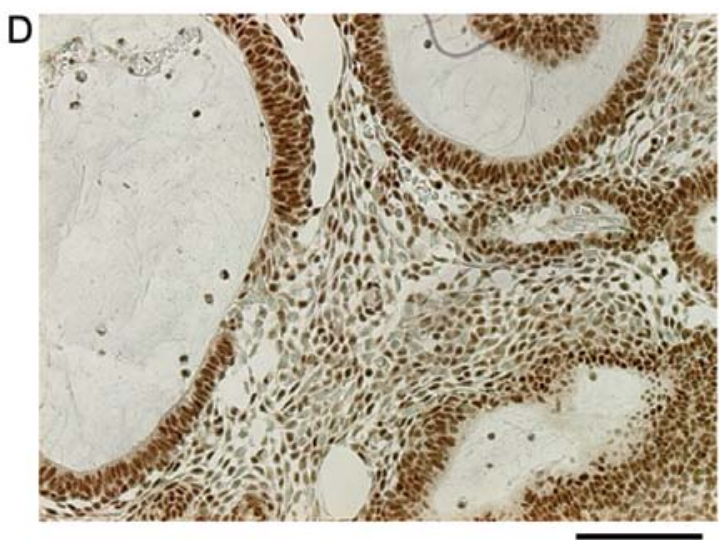

Figure 6. Immunohistochemical staining for TGF- $\beta$ and phosphorylated Smad3. Representative staining results for TGF- $\beta$ (A and B) and phosphorylated Smad3 (C and D) in the KCOT (A and C) and ameloblastoma (B and D) are shown. The bar represents $50 \mu \mathrm{m}$.
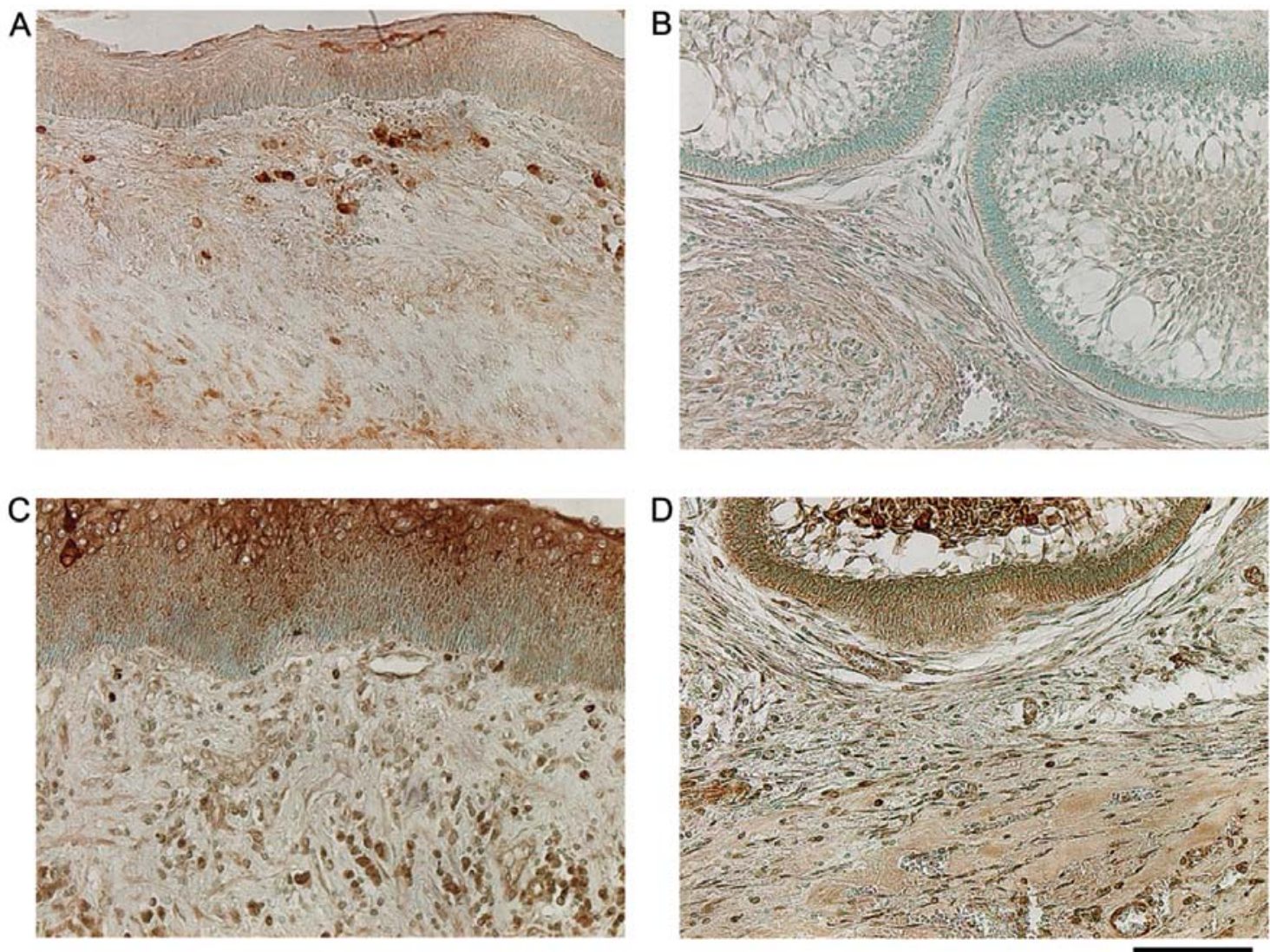

Figure 7. Immunohistochemical staining for RANKL and COX-2. Representative staining results for RANKL (A and B) and COX-2 (C and D) in the KCOT (A and C) and ameloblastoma (B and D) are shown. The bar represents $50 \mu \mathrm{m}$. 
A

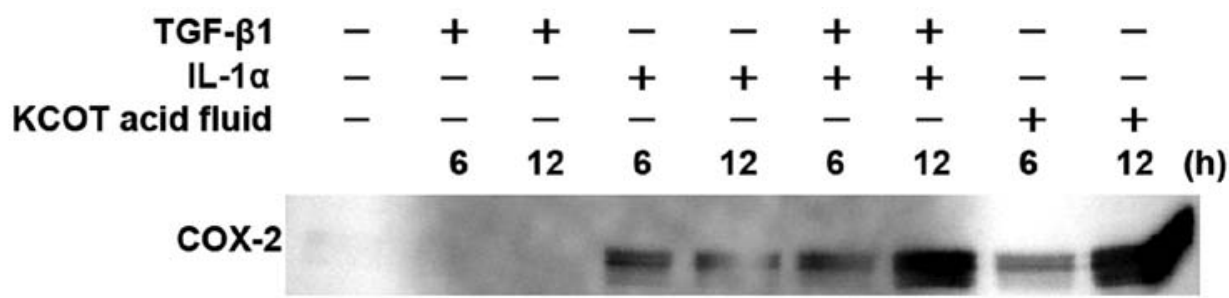

$\begin{array}{rllllll}\text { B TGF- } \beta R \text { inhibitor } & - & - & - & + & - & + \\ \text { IL-1Ra } & - & - & - & - & + & + \\ \text { TGF- } \beta 1 & - & + & - & - & - & - \\ \text { IL-1 } \alpha & - & + & - & - & - & - \\ \text { KCOT acid fluid } & - & - & + & + & + & + \\ \text { coX-2 } & & & & & & \end{array}$

Figure 8. Effects of KCOT fluid, TGF- $\beta 1$, and IL- $1 \alpha$ on COX-2 expression in KCOT stromal fibroblasts, and effects of TGF- $\beta$ receptor inhibitor and IL-1 receptor antagonist on KCOT fluid-induced COX-2 expression. (A) After culturing KCOT stromal fibroblasts for 6 or $12 \mathrm{~h}$ in the presence of TGF- $\beta 1$ (1 ng/ml), IL-1 $\alpha(1 \mathrm{ng} / \mathrm{ml})$, and $1 \%$ KCOT fluid (with or without acid treatment as indicated by KCOT acid fluid), western blotting was performed to examine COX-2 expression. Although TGF- $\beta 1$ did not increase COX-2 protein expression, IL-1 $\alpha$ did. The combination of TGF- $\beta 1$ and IL- $1 \alpha$ synergistically increased COX-2 protein expression. KCOT fluid also increased COX-2 protein expression. (B) KCOT stromal fibroblasts were cultured for $12 \mathrm{~h}$ in the presence of $1 \%$ KCOT fluid following $1 \mathrm{~h}$ of pretreatment with the TGF- $\beta$ receptor inhibitor $(1 \mu \mathrm{M})$ and IL-1 receptor antagonist $(50 \mathrm{ng} / \mathrm{ml})$. Intracystic fluid-induced COX-2 expression was not inhibited by TGF- $\beta$ receptor inhibitor, but was nearly completely inhibited by the IL- 1 receptor antagonist. The combination of TGF- $\beta$ receptor inhibitor and IL-1 $\alpha$ receptor antagonist did not inhibit COX-2 protein expression more than that inhibited by the IL-1 $\alpha$ receptor antagonist alone.

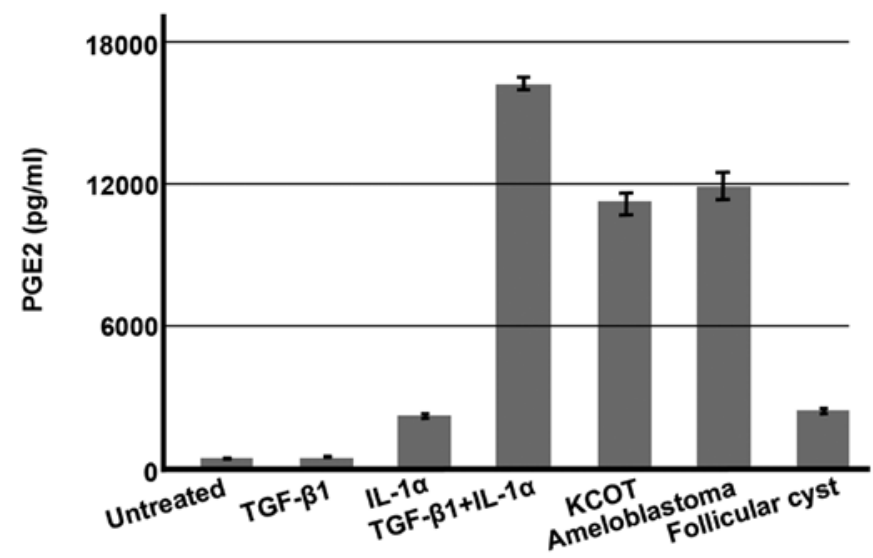

Figure 9. Concentrations of PGE2 in KCOT stromal fibroblast culture supernatant. Stromal fibroblasts were cultured for $6 \mathrm{~h}$ in the presence of TGF- $\beta$ $(1 \mathrm{ng} / \mathrm{ml}), \mathrm{IL}-1 \alpha(1 \mathrm{ng} / \mathrm{ml})$, and intracystic fluids; the concentration of PGE2 in the resulting culture supernatant was then measured. Representative results are shown. The mean concentrations of PGE2 in culture medium were $313.0 \pm 142.38$ (untreated), $403.3 \pm 83.28$ (TGF- $\beta 1$-treated), $2,160.4 \pm 65.04$ (IL-1 $\alpha$-treated), 16,046.2 \pm 264.87 (TGF- $\beta 1+$ IL-1 $\alpha$ ), $10,970.8 \pm 405.21$ (1\% KCOT-treated), 1,1683.2 \pm 602.28 ( $2 \%$ ameloblastoma fluid-treated), and $2,393.7 \pm 43.71 \mathrm{pg} / \mathrm{ml}$ ( $1 \%$ follicular cyst fluid-treated).

was not inhibited by TGF- $\beta$ receptor inhibitor alone, but was nearly completely inhibited by the IL-1 receptor antagonist. The combination of TGF- $\beta$ receptor inhibitor and IL- $1 \alpha$ receptor antagonist did not inhibit $\mathrm{COX}-2$ protein expression more than that by the IL- $1 \alpha$ receptor antagonist alone (Fig. 8B).

After culturing stromal fibroblasts for $6 \mathrm{~h}$ in the presence of KCOT fluid, TGF- $\beta 1$, IL- $1 \alpha$, and a combination of TGF- $\beta 1$ and IL- $1 \alpha$, we measured the concentration of PGE2 in the resulting supernatant. The mean concentration of PGE2 in
A
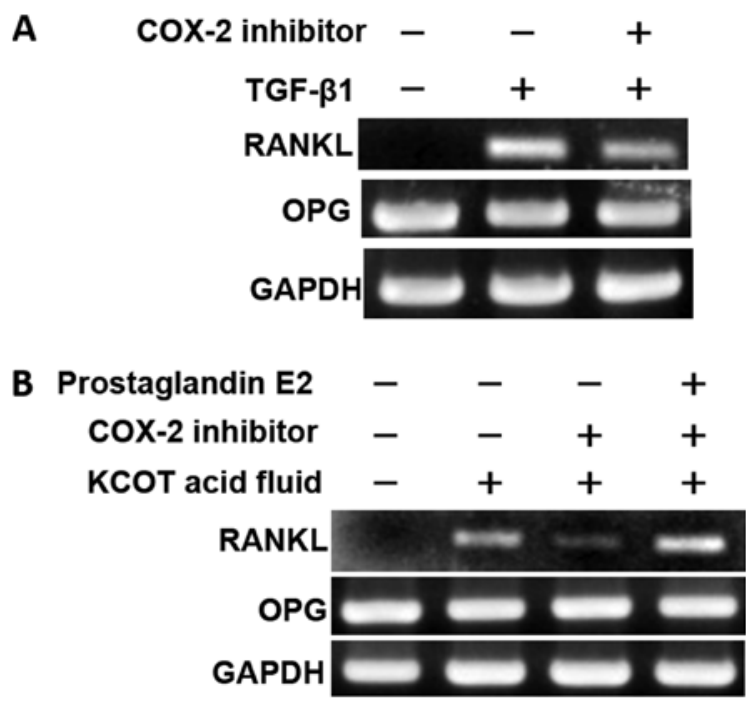

Figure 10. Effects of selective COX-2 inhibitor (CAY10404) on RANKL expression induced by TGF- $\beta$ and KCOT fluid. Following 1-h pretreatment with the selective COX-2 inhibitor $(1 \mu \mathrm{M})$, KCOT stromal fibroblasts were cultured for $12 \mathrm{~h}$ with TGF- $\beta 1(1 \mathrm{ng} / \mathrm{ml})$ and $1 \%$ KCOT fluid. RT-PCR was then used to examine RANKL expression. (A) TGF- $\beta 1$-induced RANKL expression was only weakly inhibited by the selective COX-2 inhibitor. (B) Intracystic fluid-induced RANKL expression was strongly inhibited by the selective COX-2 inhibitor; recovery from this inhibition was achieved by culture in the presence of PGE2 $(200 \mathrm{nM})$.

untreated culture medium was $313.0 \pm 142.38 \mathrm{pg} / \mathrm{ml}$. The mean concentrations of PGE2 in culture in the presence of TGF- $\beta 1$, IL- $1 \alpha$, both TGF- $\beta 1$ and IL- $1 \alpha$, KCOT fluid, ameloblastoma fluid, and follicular cyst fluid were 403.3 $\pm 83.28,2160.4 \pm 65.04$, $16046.2 \pm 264.87,10970.8 \pm 405.21,11683.2 \pm 602.28$ and $2393.7 \pm 43.71 \mathrm{pg} / \mathrm{ml}$, respectively $(\sim 1.3,6.9,51.3,35,37.3$ and 


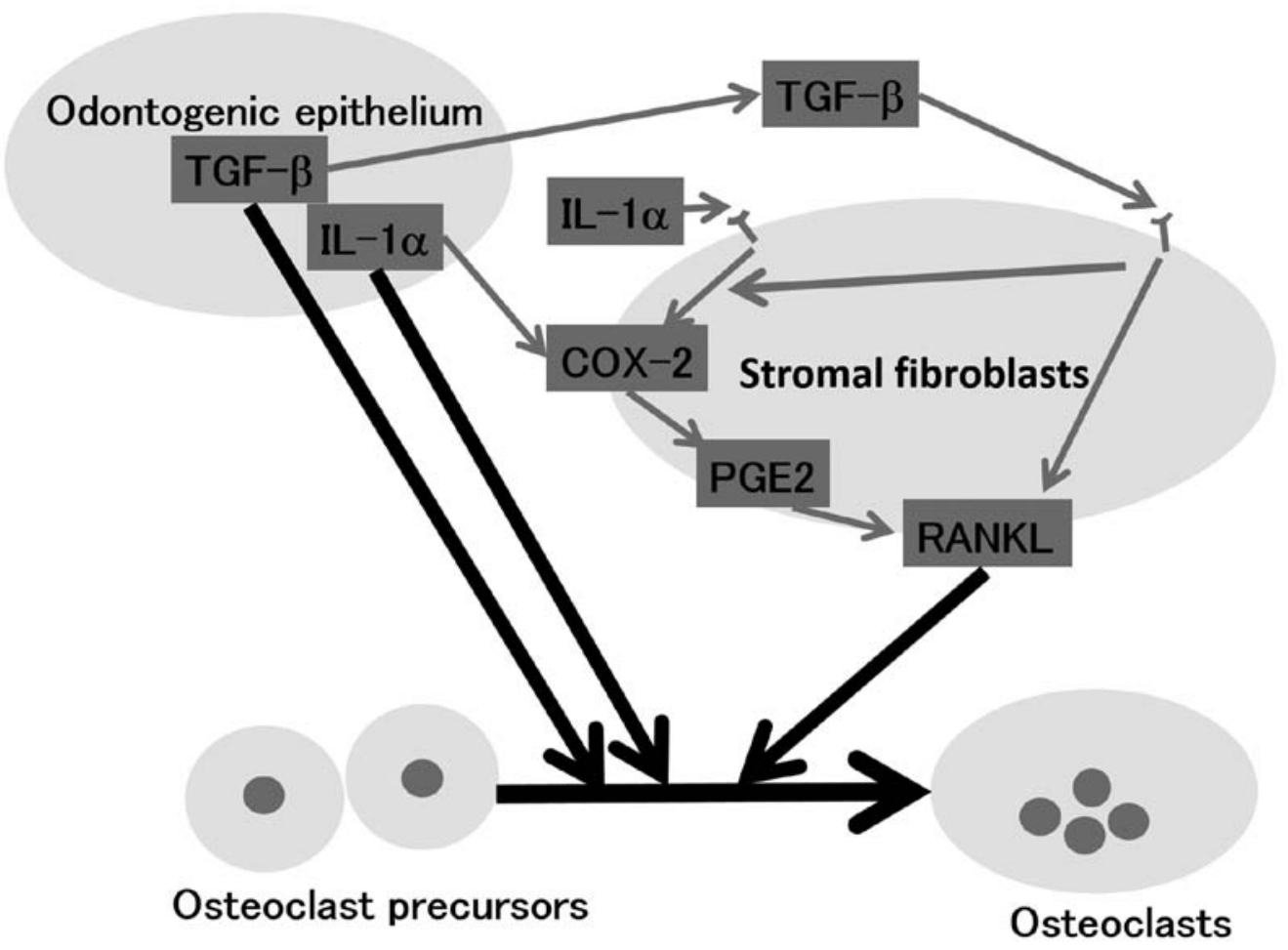

Figure 11. Mechanism underlying promotion of RANKL expression in KCOT stromal fibroblasts. It was demonstrated that TGF- $\beta$ and IL-1 $\alpha$ possess the latent capacity to directly promote osteoclast formation from osteoclast precursors and may be involved in jawbone resorption by inducing RANKL expression in stromal fibroblasts and promoting osteoclast formation. It was thus demonstrated that induction of RANKL expression in stromal fibroblasts occurs by two pathways: a TGF- $\beta$ pathway, which is not mediated by COX-2-PGE2 synthesis, and an IL- $1 \alpha$ pathway. It was also demonstrated that TGF- $\beta$ signals synergistically promote IL-1 $\alpha$ signal-induced COX-2-PGE2 synthesis, thus promoting RANKL expression.

7.6 times, respectively, higher than that yielded by untreated culture medium). While PGE2 concentrations in cultured samples of other intracystic fluids demonstrated widely varying increases from 1.4 to 537.6 times, these fluids displayed greatly increased concentrations of PGE2 (data not shown). In a mechanism consistent with the changes in COX-2 protein shown in Fig. 8A, TGF- $\beta 1$ did not promote PGE2 synthesis, whereas IL-1 $\alpha$ promoted PGE2 synthesis, and a combination of the two promoted PGE2 synthesis synergistically. In addition, PGE2 synthesis was strongly promoted by jawbone tumor and cyst fluids (Fig. 9). Finally, we examined COX-2-mediated RANKL expression in stromal fibroblasts. Following pretreatment with a selective COX-2 inhibitor, KCOT stromal fibroblasts were cultured for $12 \mathrm{~h}$ in the presence of TGF- $\beta 1$ or KCOT fluid; RT-PCR was then used to examine RANKL expression. It was found that RANKL expression induced by TGF- $\beta 1$ was only weakly inhibited by the selective COX-2 inhibitor (Fig. 10A). Moreover, RANKL expression induced by KCOT fluid was strongly inhibited by the selective COX-2 inhibitor (Fig. 10B). In addition, recovery from this inhibition was achieved by culture in the presence of PGE2, a downstream target of COX-2 (Fig. 10B).

\section{Discussion}

Recent research has suggested that RANKL is involved in all bone resorption diseases regardless of inflammation or tumor induction (1). However, although cyst epithelial cell proliferation $(16,17)$ and resorption resulting from intracystic fluid-induced compression $(18,19)$ have long been proposed as mechanisms for the enlargement of maxillary tumors and cysts and have garnered widespread acceptance, no action has been taken on these proposals. Therefore, we determined whether the cytokines and stromal fibroblasts produced by odontogenic tumors and cysts are involved in osteoclast formation and to determine the molecular mechanism underlying this involvement. To address these points, we focused on the role of TGF- $\beta$ and IL- $1 \alpha$, and we analyzed the mechanism underlying osteoclast formation. Direct isolation of cytokines produced by odontogenic epithelial cells is technically difficult, and cytokines produced extracellularly were thought to be present in intracystic fluid. Therefore, by the stimulation of intracyctic cytokines, we investigated the regulation of RANKL expression, an osteoclast formation-inducing factor, in stromal fibroblasts.

In this study, KCOT fluid induced RANKL expression in stromal fibroblasts. This effect was enhanced on treating KCOT fluid with an acid (Fig. 1). Because TGF- $\beta$ is known to be activated by acid treatment, we believed that TGF- $\beta$ was present in KCOT fluid and was involved in RANKL expression. TGF- $\beta 1$ induced RANKL expression in KCOT stromal fibroblasts in a concentration-dependent manner (Fig. 2A). RANKL expression was induced in a time-dependent manner from 3 to $12 \mathrm{~h}$ of culture and was attenuated beyond $24 \mathrm{~h}$ (data not shown). In TGF- $\beta$ signal transduction, Smad2/3 is characteristically phosphorylated (9). Although KCOT fluid stimulation resulted in phosphorylation of Smad3 in KCOT stromal fibroblasts (Fig. 3A), phosphorylation of Smad2 was 
not detected with TGF- $\beta$ stimulation (data not shown). Thus, the results in KCOT stromal fibroblasts suggested that TGF- $\beta 1$ activates Smad3 and exerts a biochemical effect. Treatment of KCOT fluid and KCOT stromal fibroblasts with anti-TGF- $\beta$ antibody and TGF- $\beta$ receptor inhibitor, respectively, inhibited the induction of RANKL expression (Fig. 3B). These results suggested that TGF- $\beta$ is present in KCOT fluid and that TGF- $\beta$ receptors activate $\mathrm{Smad} 3$ and induce RANKL expression in KCOT stromal fibroblasts.

The effects of TGF- $\beta$ in relation to the regulation of RANKL and OPG expression in osteoblasts, as reported in previous studies, differ from the results obtained in stromal fibroblasts in this study as well as that obtained in a report on the effects of TGF- $\beta$ in tooth germ fibroblasts (11). In particular, these past reports stated that TGF- $\beta$ inhibited RANKL expression and promoted OPG expression $(22,23)$. However, TGF- $\beta$ increases RANKL expression in human osteoblasts isolated from clinical samples (24). Thus, it is possible that the mechanism by which TGF- $\beta$ regulates RANKL expression differs according to the type of cell and stage of cell differentiation. It is also possible that RANKL expression in odontogenic tumor and cyst stromal and tooth germ fibroblasts (11) is promoted by TGF- $\beta$.

KCOT fluid-induced RANKL expression was not completely inhibited by TGF- $\beta$ antibody or TGF- $\beta$ receptor inhibitor (Fig. 3B), but was completely inhibited by the IL-1 receptor antagonist (Fig. 4). This finding demonstrated that TGF- $\beta 1$ and IL- $1 \alpha$ in intracystic fluid induce RANKL expression in stromal fibroblasts. IL-1 $\alpha$ promotes RANKL expression in KCOT stromal fibroblasts (20). In this study, IL- $1 \alpha$ consistently induced RANKL expression in KCOT stromal fibroblasts (Fig. 2B), a result which is consistent with that observed in previous studies.

Both TGF- $\beta 1$ and IL- $1 \alpha$ were present in KCOT fluid in high concentrations. In addition, the concentrations of TGF- $\beta 1$ and IL- $1 \alpha$ in ameloblastoma fluid, though lower than that in KCOT fluid, were nonetheless high. The concentration of TGF- $\beta 1$ in follicular cyst fluid, though lower than that in KCOT fluid, was still high, and the concentration of IL-1 $\alpha$ was low. The concentration of IL-1 $\alpha$ in KCOT fluid is high, whereas the concentration of IL-6 in ameloblastoma fluid is high and shows disease specificity (25). In the results of this study as well KCOT fluid showed high concentrations of both TGF- $\beta 1$ and IL- $1 \alpha$; this characteristic distinguishes KCOT from follicular cysts in which concentrations of IL- $1 \alpha$ are low and suggests that TGF- $\beta 1$ and IL- $1 \alpha$ are disease specific and concentration of IL- $1 \alpha$ could be used as a clinical marker to distinguish between these two lesions.

In immunohistochemical staining, KCOT and ameloblastoma epithelial cells were positive for TGF- $\beta$, which is consistent with the results of previous studies $(26,27)$. Furthermore, immunohistochemical results for TGF- $\beta$ and phosphorylated Smad3 demonstrated that TGF- $\beta$ is produced by odontogenic epithelial cells and Smad3 is activated in the epithelial tissue and stromal fibroblasts, thus triggering intracellular signal transduction. In addition, RANKL expression was confirmed in the KCOT and ameloblastoma interstitial tissue (Fig. 7A and B). Epithelial cells were also positive for RANKL. RANKL is expressed in vitro in ameloblastomaderived epithelial cells (28) and that ameloblastoma epithelial cells are positive for RANKL staining $(29,30)$; however, the function of RANKL in ameloblastoma remains unknown and thus must be further investigated.

PGE2, which is synthesized by COX in the arachidonic acid cascade, is a biologically active substance that strongly promotes RANKL expression (31). In addition, COX exists both as COX-1 and COX-2. Although COX-1 is constantly expressed in cells and involved in the production of PGE2, which is necessary for physiological functions, COX-2 is expressed only when induced by stimuli, such as cytokines and growth factors, and is known to temporarily increase production of tissue-specific PGE2 (32). Therefore, regulation of inducible COX-2 expression is important for synthesis of PGE2 by cellular stimulation. IL-1 $\alpha$ promotes RANKL expression via synthesis of COX-2 and PGE2 (20,21).

This study determined that TGF- $\beta$ and IL- $1 \alpha$ induce RANKL expression in KCOT stromal fibroblasts. Based on this finding and on the fact that a combination of the above two factors enhanced induction of RANKL expression (Fig. 2C), we investigated the involvement of COX-2 and PGE2 in TGF- $\beta$-induced RANKL expression. We determined that although TGF- $\beta 1$ did not promote synthesis of COX-2 protein or PGE2 in stromal fibroblasts, it did synergistically promote IL- $1 \alpha$-induced synthesis of COX-2 protein and PGE2 (Figs. 8 and 9). Also, although TGF- $\beta 1$-induced RANKL expression was only weakly inhibited by a selective COX-2 inhibitor, intracystic fluid-induced RANKL expression was strongly inhibited by the selective COX-2 inhibitor (Fig. 10). IL- $1 \alpha$-induced RANKL expression, which is mediated by COX-2/PGE2 synthesis, may have been inhibited and thus TGF- $\beta 1$-induced RANKL expression was observed, which is not mediated by COX-2/PGE2 synthesis. The above findings demonstrate that induction of RANKL expression in stromal fibroblasts occurs by two pathways: a TGF- $\beta$ pathway, which is not mediated by COX-2/PGE2 synthesis, and an IL- $1 \alpha$ pathway. It was also demonstrated that TGF- $\beta$ signals synergistically promote IL-1 $\alpha$ signal-induced COX-2/PGE2 synthesis, thus promoting RANKL expression.

In addition, TGF- $\beta$ and IL- $1 \alpha$ act directly on osteoclast precursors and promote osteoclast differentiation $(14,15)$. TGF- $\beta$ promoted RANKL-dependent osteoclast differentiation of human peripheral blood mononuclear cells and murine macrophage-like cell line RAW264, which are osteoclast precursors, and IL- $1 \alpha$ also promoted osteoclast differentiation of the murine macrophage-like cell line RAW264 (data not shown).

The experiments described above demonstrated that TGF- $\beta$ and IL- $1 \alpha$, cytokines which are produced by KCOT, ameloblastoma, and follicular cyst epithelial cells, possess the latent capacity to directly promote osteoclast formation from osteoclast precursors and may be involved in jawbone resorption by inducing RANKL expression in stromal fibroblasts and promoting osteoclast formation (Fig. 11). Previously reported mechanisms of growth of jawbone tumors, growth of cysts in the jawbone, and bone resorption include proliferation of cyst epithelial cells $(16,17)$ and intracystic fluid-induced compressive resorption $(18,19)$. The results of this study demonstrate the involvement of another mechanism in which TGF- $\beta 1$ and IL-1 $\alpha$ produced by the jawbone tumor and cyst epithelial cells induce RANKL expression in stromal fibroblasts and promote 
osteoclast formation. We believe that these findings will help in elucidating the mechanism underlying bone resorption in primary lesions.

\section{Acknowledgements}

This study was supported by a Grant-in-Aid for Scientific Research from Japan Society for the Promotion of Science (no. 24592986 and no. 16K11682 to T.A., no. 21592523 to S.I. and T.A., and no. 25893125 to C.Y.).

\section{References}

1. Kong YY, Feige U, Sarosi I, Bolon B, Tafuri A, Morony S, Capparelli C, Li J, Elliott R, McCabe S, et al: Activated T cells regulate bone loss and joint destruction in adjuvant arthritis through osteoprotegerin ligand. Nature 402: 304-309, 1999.

2. Nakashima $\mathrm{T}$ and Takayanagi $\mathrm{H}$ : Osteoclasts and the immune system. J Bone Miner Metab 27: 519-529, 2009.

3. Takayanagi H, Oda H, Yamamoto S, Kawaguchi H, Tanaka S, Nishikawa $\mathrm{T}$ and Koshihara Y: A new mechanism of bone destruction in rheumatoid arthritis: Synovial fibroblasts induce osteoclastogenesis. Biochem Biophys Res Commun 240 279-286, 1997.

4. Takayanagi H, Iizuka H, Juji T, Nakagawa T, Yamamoto A, Miyazaki T, Koshihara Y, Oda H, Nakamura K and Tanaka S: Involvement of receptor activator of nuclear factor kappaB ligand/osteoclast differentiation factor in osteoclastogenesis from synoviocytes in rheumatoid arthritis. Arthritis Rheum 43: 259-269, 2000

5. Nagai M, Kyakumoto S and Sato N: Cancer cells responsible for humoral hypercalcemia express mRNA encoding a secreted form of ODF/TRANCE that induces osteoclast formation. Biochem Biophys Res Commun 269: 532-536, 2000.

6. Kawai T, Matsuyama T, Hosokawa Y, Makihira S, Seki M, Karimbux NY, Goncalves RB, Valverde P, Dibart S, Li YP, et al: $\mathrm{B}$ and $\mathrm{T}$ lymphocytes are the primary sources of RANKL in the bone resorptive lesion of periodontal disease. Am J Pathol 169: 987-998, 2006.

7. Philbrick WM, Dreyer BE, Nakchbandi IA and Karaplis AC: Parathyroid hormone-related protein is required for tooth eruption. Proc Natl Acad Sci USA 95: 11846-11851, 1998.

8. Kitahara Y, Suda N, Kuroda T, Beck F, Hammond VE and Takano Y: Disturbed tooth development in parathyroid hormonerelated protein (PTHrP)-gene knockout mice. Bone 30: 48-56, 2002.

9. Miyazono K, ten Dijke P and Heldin CH: TGF-beta signaling by Smad proteins. Adv Immunol 75: 115-157, 2000.

10. Allan SM, Tyrrell PJ and Rothwell NJ: Interleukin-1 and neuronal injury. Nat Rev Immunol 5: 629-640, 2005.

11. Wise GE, Frazier-Bowers S and D'Souza RN: Cellular, molecular, and genetic determinants of tooth eruption. Crit Rev Oral Biol Med 13: 323-334, 2002.

12. Yao S, Ring S, Henk WG and Wise GE: In vivo expression of RANKL in the rat dental follicle as determined by laser capture microdissection. Arch Oral Biol 49: 451-456, 2004.

13. Liu D, Yao S, Pan F and Wise GE: Chronology and regulation of gene expression of RANKL in the rat dental follicle. Eur J Oral Sci 113: 404-409, 2005.

14. Fox SW and Lovibond AC: Current insights into the role of transforming growth factor-beta in bone resorption. Mol Cell Endocrinol 243: 19-26, 2005.

15. Kim JH, Jin HM, Kim K, Song I, Youn BU, Matsuo K and Kim N: The mechanism of osteoclast differentiation induced by IL-1. J Immunol 183: 1862-1870, 2009.
16. Thosaporn W, Iamaroon A, Pongsiriwet S and $\mathrm{Ng} \mathrm{KH}$ : A comparative study of epithelial cell proliferation between the odontogenic keratocyst, orthokeratinized odontogenic cyst, dentigerous cyst, and ameloblastoma. Oral Dis 10: 22-26, 2004.

17. el Murtadi A, Grehan D, Toner M and McCartan BE: Proliferating cell nuclear antigen staining in syndrome and nonsyndrome odontogenic keratocysts. Oral Surg Oral Med Oral Pathol Oral Radiol Endod 81: 217-220, 1996.

18. Kubota Y, Yamashiro T, Oka S, Ninomiya T, Ogata S and Shirasuna K: Relation between size of odontogenic jaw cysts and the pressure of fluid within. Br J Oral Maxillofac Surg 42: 391-395, 2004.

19. Marker P, Brøndum N, Clausen PP and Bastian HL: Treatment of large odontogenic keratocysts by decompression and later cystectomy: A long-term follow-up and a histologic study of 23 cases. Oral Surg Oral Med Oral Pathol Oral Radiol Endod 82: 122-131, 1996.

20. Oka S, Kubota Y, Yamashiro T, Ogata S, Ninomiya T, Ito S and Shirasuna K: Effects of positive pressure in odontogenic keratocysts. J Dent Res 84: 913-918, 2005.

21. Ogata S, Kubota Y, Yamashiro T, Takeuchi H, Ninomiya T, Suyama Y and Shirasuna K: Signaling pathways regulating IL-1alpha-induced COX-2 expression. J Dent Res 86: 186-191, 2007.

22. Takai H, Kanematsu M, Yano K, Tsuda E, Higashio K, Ikeda K, Watanabe K and Yamada Y: Transforming growth factor-beta stimulates the production of osteoprotegerin/osteoclastogenesis inhibitory factor by bone marrow stromal cells. J Biol Chem 273 . 27091-27096, 1998.

23. Quinn JM, Itoh K, Udagawa N, Hausler K, Yasuda H, Shima N, Mizuno A, Higashio K, Takahashi N, Suda T, et al: Transforming growth factor beta affects osteoclast differentiation via direct and indirect actions. J Bone Miner Res 16: 1787-1794, 2001.

24. Jurado S, Garcia-Giralt N, Díez-Pérez A, Esbrit P, Yoskovitz G, Agueda L, Urreizti R, Pérez-Edo L, Saló G, Mellibovsky L, et al: Effect of IL-1beta, PGE(2), and TGF-beta1 on the expression of OPG and RANKL in normal and osteoporotic primary human osteoblasts. J Cell Biochem 110: 304-310, 2010.

25. Kubota Y, Nitta S, Oka S, Nakagawa S, Ninomiya T and Shirasuna K: Discrimination of ameloblastomas from odontogenic keratocysts by cytokine levels and gelatinase species of the intracystic fluids. J Oral Pathol Med 30: 421-427, 2001.

26. Piattelli A, Rubini C, Fioroni M, Favero L and Strocchi R: Expression of transforming growth factor-beta 1 (TGF-beta 1) in odontogenic cysts. Int Endod J 37: 7-11, 2004.

27. Kumamoto H, Yoshida M and Ooya K: Immunohistochemical detection of hepatocyte growth factor, transforming growth factor-beta and their receptors in epithelial odontogenic tumors. J Oral Pathol Med 31: 539-548, 2002.

28. Sandra F, Hendarmin L, Kukita T, Nakao Y, Nakamura N and Nakamura S: Ameloblastoma induces osteoclastogenesis: A possible role of ameloblastoma in expanding in the bone. Oral Oncol 41: 637-644, 2005.

29. Tay JY, Bay BH, Yeo JF, Harris M, Meghji S and Dheen ST: Identification of RANKL in osteolytic lesions of the facial skeleton. J Dent Res 83: 349-353, 2004.

30. da Silva TA, Batista AC, Mendonça EF, Leles CR, Fukada S and Cunha FQ: Comparative expression of RANK, RANKL, and OPG in keratocystic odontogenic tumors, ameloblastomas, and dentigerous cysts. Oral Surg Oral Med Oral Pathol Oral Radiol Endod 105: 333-341, 2008.

31. Blackwell KA, Raisz LG and Pilbeam CC: Prostaglandins in bone: Bad cop, good cop? Trends Endocrinol Metab 21: 294-301, 2010.

32. Vane J: Towards a better aspirin. Nature 367: 215-216, 1994. 